\title{
CatApp: A web application for surface chemistry and heterogeneous catalysis
}

\author{
J. S. Hummelshøj ${ }^{\text {a }}$, F. Abild-Pedersen ${ }^{\text {a }}$, F. Studt ${ }^{\mathrm{a}}$, T. Bligaard ${ }^{\mathrm{a}}$, J. K. Nørskov ${ }^{\mathrm{a}, \mathrm{b}}$
}

SUNCAT Center for Interface Science and Catalysis, aSLAC National Accelerator Laboratory, 2575 Sand Hill Road, Menlo Park, CA 94025

bDepartment of Chemical Engineering, Stanford University, Stanford, CA 94305

We introduce a web application (CatApp) for looking up calculated reaction and activation energies for elementary coupling reactions occurring on metal surfaces. It provides access to reaction and activation energies for all reactions involving $C-C, C-H$, $\mathrm{C}-\mathrm{O}, \mathrm{O}-\mathrm{O}, \mathrm{O}-\mathrm{H}, \mathrm{N}-\mathrm{N}, \mathrm{C}-\mathrm{N}, \mathrm{O}-\mathrm{N}, \mathrm{N}-\mathrm{H}$ splitting/formation for molecules with up to three $C, N$, or $O$ atoms on a number of different facets and steps of 15 transition metals. The underlying dataset is generated from a consistent set of density functional theory calculations and extrapolations based on linear scaling relations. The application is the first example of a publicly accessible web interface to the Quantum Materials Informatics Project.

Solid catalysts form the backbone of the chemical industry and the hydrocarbon-based energy sector. Most catalysts and processes today are highly optimized, but there is still considerable room for improvements in reactivity and selectivity that would lower energy consumption and waste production. In addition there are tremendous challenges to catalysis science and engineering in developing a sustainable energy solutions. The ability to store solar energy as a fuel calls for new catalysts and so does the development of a sustainable chemical industry based on biomass and other non-fossil building blocks.

The development of new catalysts could be accelerated significantly if we had access to systematic data for activation energies of elementary surface reactions. Once the key parameters determining the activity or selectivity of a certain process has been established though experiments or calculations, such a database would enable searches for new catalyst leads. Ideally, data would come from detailed, systematic experiments, but it is in general not possible to find such data. Electronic structure calculations provide a powerful alternative. The accuracy is not such that detailed predictions of absolute rates of elementary reaction steps can be made, but for classes of interesting catalysts (transition metals) it is possible to create systematic data with sufficient accuracy to predict trends in reactivity.[1-16] In the present paper, we introduce such a set of calculated reaction energies and activation energies for a large number of elementary surface reactions on a series of metal single crystal surfaces including surfaces with defects such as steps. We will also introduce a simple web application (CatApp) that can be downloaded to access these data. The data will be part of a larger database of surface reaction data that are being developed under the Quantum Materials Informatics Project, see ref. [http://www.qmip.org]. 
The database includes reaction energies for all surface reactions involving $\mathrm{C}-\mathrm{C}, \mathrm{C}-\mathrm{H}, \mathrm{C}-$ $\mathrm{O}, \mathrm{O}-\mathrm{O}, \mathrm{O}-\mathrm{H}, \mathrm{N}-\mathrm{N}, \mathrm{C}-\mathrm{N}, \mathrm{O}-\mathrm{N}, \mathrm{N}-\mathrm{H}$ splitting for molecules with up to three $\mathrm{C}, \mathrm{N}$, or O atoms on close-packed fcc(111), hcp(0001), and bcc(110) surfaces as well as stepped fcc and hcp surfaces. The metals included in the database are $\mathrm{Ag}, \mathrm{Au}, \mathrm{Co}, \mathrm{Cu}, \mathrm{Fe}, \mathrm{Ir}, \mathrm{Mo}$, $\mathrm{Ni}, \mathrm{Pd}, \mathrm{Pt}, \mathrm{Re}, \mathrm{Rh}, \mathrm{Ru}, \mathrm{Sc}, \mathrm{V})$. The data have been compiled from publications, [17-22] where the details of the calculations can be found. The important point here is that they have all been calculated with the same code (DACAPO), the same exchange-correlation energy functional (GGA-RPBE), [23] and similar calculational parameters. This means that one adsorption energy or reaction barrier can be compared to another with some confidence. $\mathrm{CO}_{2}$ and $\mathrm{O}_{2}$ for which the RPBE functional performs poorly where corrected as described in refs [24] and [25], respectively.

In cases where there are no calculated data for a given reaction, we use the recently developed scaling relations to provide an estimate. The scaling relations link the adsorption energies of different molecules containing varying amounts of hydrogen.[17] In a similar fashion we exploit the fact that transition state energies are found to scale with reaction energies.[1, 21, 26]

We have developed a simple visual query tool for accessing the data presented above. On the homepage http://suncat.slac.stanford.edu/catapp/ we maintain a list of hyperlinks to the available versions of the tool together with a list of references to the scientific data it employs. The tool itself is implemented in JavaScript, SVG, and HTML and runs in modern web-browsers without any plug-ins. It can easily be used in portable devices with a touch interface. Using the application one can choose a surface and an elementary reaction and be presented with a reaction path reporting the reaction and activation energy. If a DFT value is not found for a given reaction and a scaling estimate is used, this is indicated by showing the value in italic.

In Figure 1 we have shown an example of the use of the application. The energy barrier needed to break the $\mathrm{N}_{2}$ bond on two different surface orientations of ruthenium, $\mathrm{Ru}(0001)$ and stepped $\mathrm{Ru}(0001)$, are extracted. The plots immediately show the structure dependence of this important step in the Haber-Bosch process $\left(\mathrm{N}_{2}+3 \mathrm{H}_{2}->2 \mathrm{NH}_{3}\right)$.

Our web application will allow anyone to download data like shown in Figure 1 and to quickly explore whether there may be other metals or structures where the $\mathrm{N}_{2}$ bond is broken more readily.

All code and data are downloaded when the application is accessed the first time and kept in the local storage of the browser. This allows the application to be used even when the user has no Internet connection. More importantly, it guarantees the user complete privacy since all queries are performed locally in the browser and not via calls to our server. The only information that is delivered from the user to our server is an anonymous 
transfer of the number of queries that have been executed since the last time the application was started while connected to the Internet. This will be used to monitor the use of the tool. On startup the application will look for any updates to the application code or newly available data and seamlessly update itself.
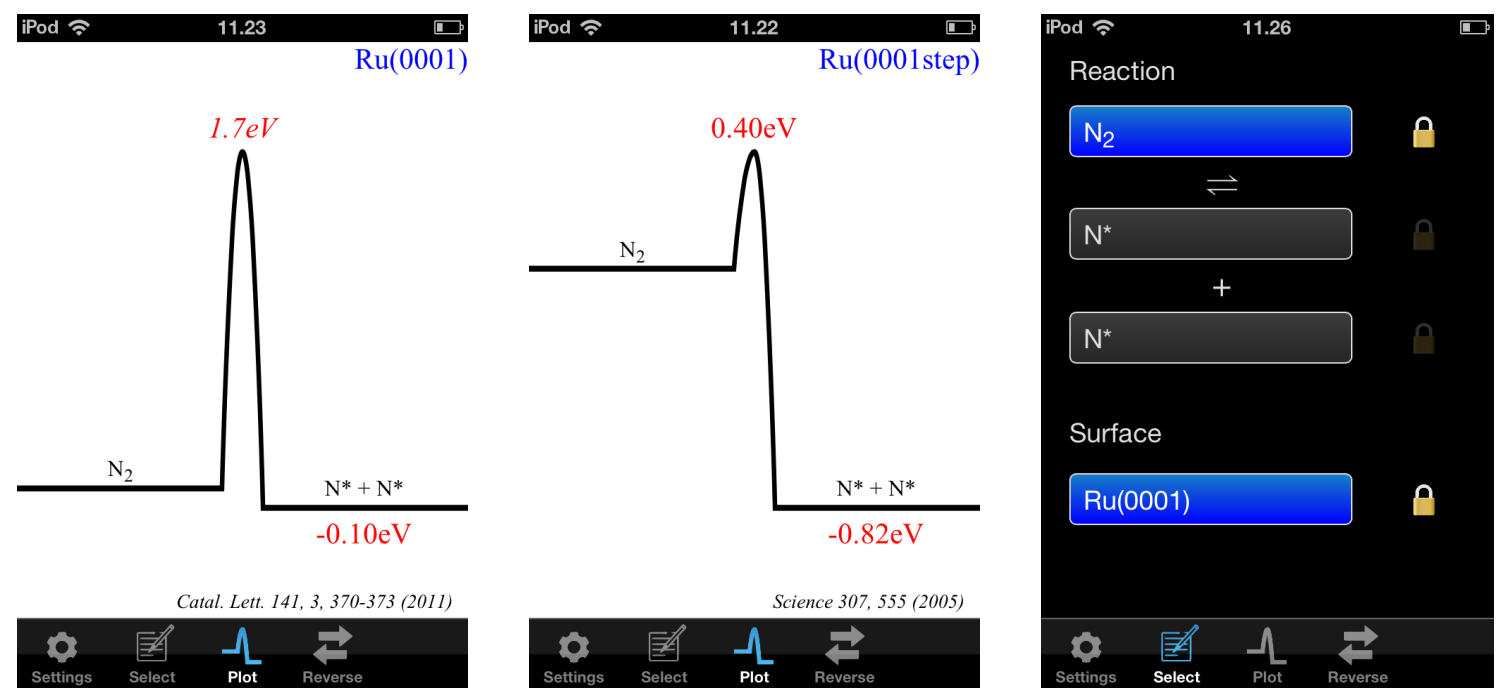

Figure 1. Screenshots from the app. Two leftmost panels: $N_{2}$ splitting on Ru(0001) and on stepped Ru(0001), respectively. Right panel: In the select view the user can from dropdown menus choose the reaction parameters $(A B, A, B)$ and the surface parameter. When a parameter has been selected the CatApp dynamically hides values of the unselected parameters for which neither DFT nor scaling energies are available.

The data shown in Figure 1 are direct copies of the output from the CatApp running on a Smart Phone. They are obtained by simply choosing the surface, the reactant and the products from fall-down menus on the screen as shown in Figure 1.

The database and web-tool presented above is a simple forerunner of what will be available in the future. The database is a small subset of the calculated surface reactivity data that will be available under the Quantum Materials Informatics Project [www.qmip.org]. The hope is that in the near future the database will contain data from many researchers and research groups, submitting their data to the database upon publication.

There is ample scope for making the database better and more useful by including coverage dependencies, [27] by including more surface structures including nanoparticles so small that they cannot be viewed as composed of independent facets, [28] and by including uncertainties in the calculations.[29] Alloy data will be uploaded next, and as more accurate exchange-correlation functionals become available, such data will be made available as well. This will include data for reactions on oxide, carbide, nitride and sulfide surfaces. 
The query application, CatApp that we have introduced here can provide the most basic tool for looking up reaction energies and activation energies. Again there is ample room for introducing other tools, such as search tools, tools to correlate data (including the option of correlating measured data with the database), and tools to display calculated spectroscopic data for direct comparison to experiments. Another potentially useful option is to couple the query tool to standard databases of experimental data for gas phase molecules and bulk solids like the NIST chemistry web-book [http://webbook.nist.gov/chemistry/], and, eventually, to experimental data for surface reactions.

All data in the database will be published data. The data will be tagged by a reference and the authors involved. A query tool like CatApp will have the option of displaying all data or data from selected authors or papers. This means that users of the data must refer to the respective papers if they want to include them in a publication of their own.

There is at least one other database of calculated properties of solids in existence focused at the moment on bulk materials for battery electrodes.[30] It will be highly desirable to be able to couple these and others databases together, but at the present stage the main challenge is to get started on a surface reactivity database and get the community to provide data and use them. Easy access to data by everybody, theorists and experimentalists, academia and industry is essential, and it is in that spirit that the first attempt at a Surface Reactivity and Catalysis Tool is hereby introduced.

[1] J.K. Norskov, T. Bligaard, A. Logadottir, S. Bahn, L.B. Hansen, M. Bollinger, H. Bengaard, B. Hammer, Z. Sljivancanin, M. Mavrikakis, Y. Xu, S. Dahl, C.J.H. Jacobsen, J. Catal. 2002 , 209, 275.

[2] J. Greeley, I.E.L. Stephens, A.S. Bondarenko, T.P. Johansson, H.A. Hansen, T.F. Jaramillo, J. Rossmeisl, I. Chorkendorff, J.K. Norskov, Nat. Chem. 2009, 1, 552.

[3] G. Ceder, Y.M. Chiang, D.R. Sadoway, M.K. Aydinol, Y.I. Jang, B. Huang, Nature 1998, 392, 694.

[4] S. Chretien, H. Metiu, J. Phys. Chem. C 2011, 115, 4696.

[5] R.B. Getman, Y. Xu, W.F. Schneider, J. Phys. Chem. C 2008, 112, 9559.

[6] L.C. Grabow, M. Mavrikakis, ACS Catal. 2011, 1, 365.

[7] J.R. Kitchin, Phys. Rev. B $\mathbf{2 0 0 9 , ~ 7 9 , ~} 205412$.

[8] G. Kresse, J. Hafner, Surf. Sci. $2000,459,287$.

[9] P. Liu, J. Chem. Phys. $2010,133,204705$.

[10] N. Lopez, T.V.W. Janssens, B.S. Clausen, Y. Xu, M. Mavrikakis, T. Bligaard, J.K. Norskov, J. Catal. $\mathbf{2 0 0 4}, 223,232$.

[11] J.K. Norskov, M. Scheffler, H. Toulhoat, MRS Bull. $2006,31,669$.

[12] G. Pacchioni, C. Di Valentin, D. Dominguez-Ariza, F. Illas, T. Bredow, T. Kluner, V. Staemmler, J. Phys.-Condes. Matter $\mathbf{2 0 0 4}, 16$, S2497.

[13] V. Pallassana, M. Neurock, V.S. Lusvardi, J.J. Lerou, D.D. Kragten, R.A. van Santen, J. Phys. Chem. B $2002,106,1656$.

[14] J.A. Swisher, N. Hansen, T. Maesen, F.J. Keil, B. Smit, A.T. Bell, J. Phys. Chem. C 2010, 114, 10229.

[15] L.J. Xu, G. Henkelman, C.T. Campbell, H. Jonsson, Phys. Rev. Lett. 2005 , 95, 146103.

[16] D. Loffreda, F. Delbecq, F. Vigne, P. Sautet, Angew. Chem.-Int. Edit. 2009 , 48, 8978.

[17] F. Abild-Pedersen, J. Greeley, F. Studt, J. Rossmeisl, T.R. Munter, P.G. Moses, E. Skulason, T. Bligaard, J.K. Norskov, Phys. Rev. Lett. $2007,99,016105$.

[18] L.C. Grabow, F. Studt, F. Abild-Pedersen, V. Petzold, J. Kleis, T. Bligaard, J.K. Norskov, Angew. Chem.-Int. Edit. $2011,50,4601$. 
[19] G. Jones, J.G. Jakobsen, S.S. Shim, J. Kleis, M.P. Andersson, J. Rossmeisl, F. Abild-Pedersen, T. Bligaard, S. Helveg, B. Hinnemann, J.R. Rostrup-Nielsen, I. Chorkendorff, J. Sehested, J.K. Norskov, J. Catal. $2008,259,147$.

[20] G. Jones, F. Studt, F. Abild-Pedersen, J.K. Norskov, T. Bligaard, Chem. Eng. Sci. $2011,66,6318$.

[21] S.G. Wang, B. Temel, J.A. Shen, G. Jones, L.C. Grabow, F. Studt, T. Bligaard, F. Abild-Pedersen, C.H. Christensen, J.K. Norskov, Catal. Lett. $2011,141,370$.

[22] S. Dahl, A. Logadottir, R.C. Egeberg, J.H. Larsen, I. Chorkendorff, E. Tornqvist, J.K. Norskov, Phys. Rev. Lett. 1999, 83, 1814.

[23] B. Hammer, L.B. Hansen, J.K. Norskov, Phys. Rev. B 1999, 59, 7413.

[24] A.A. Peterson, F. Abild-Pedersen, F. Studt, J. Rossmeisl, J.K. Norskov, Energy Environ. Sci. 2010 , 3,1311 .

[25] J. Rossmeisl, A. Logadottir, J.K. Norskov, Chem. Phys. 2005, 319, 178.

[26] A. Michaelides, Z.P. Liu, C.J. Zhang, A. Alavi, D.A. King, P. Hu, J. Am. Chem. Soc. 2003, 125, 3704.

[27] N. Inoglu, J.R. Kitchin, Phys. Rev. B $2010,82$.

[28] J. Kleis, J. Greeley, N.A. Romero, V.A. Morozov, H. Falsig, A.H. Larsen, J. Lu, J.J. Mortensen, M. Dulak, K.S. Thygesen, J.K. Norskov, K.W. Jacobsen, Catal. Lett. $2011,141,1067$.

[29] J.J. Mortensen, K. Kaasbjerg, S.L. Frederiksen, J.K. Norskov, J.P. Sethna, K.W. Jacobsen, Phys. Rev. Lett. $2005,95,216401$.

[30] G. Ceder, D. Morgan, C. Fischer, K. Tibbetts, S. Curtarolo, MRS Bull. 2006, 31, 981. 